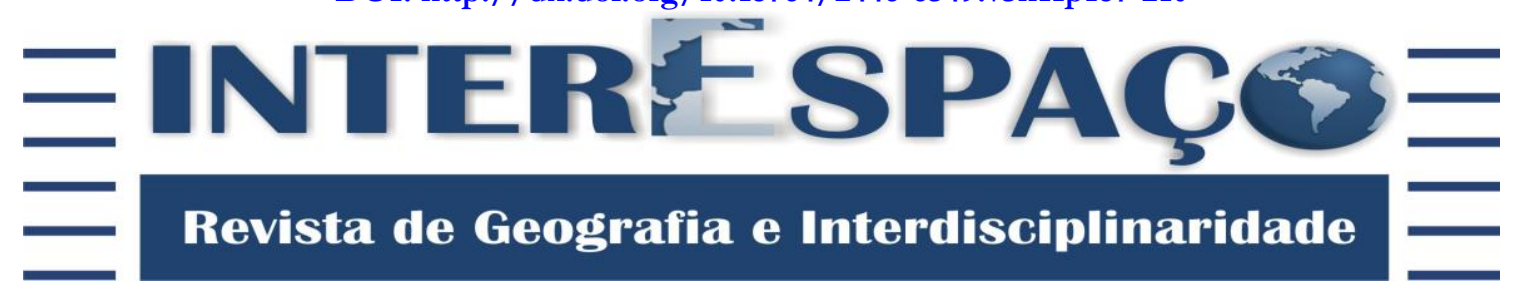

\title{
CONTRIBUIÇÕES DA EDUCAÇÃO ASSISTIDA POR ANIMAIS - EAA PARA A PSICOLOGIA DA EDUCAÇÃO: uma análise fenomenológica ${ }^{1}$
}

\section{CONTRIBUTIONS OF ANIMAL-ASSISTED EDUCATION - EAA FOR THE PSYCHOLOGY OF EDUCATION: a phenomenological analysis}

\section{CONTRIBUCIONES DE LA EDUCACIÓN ASISTIDA POR ANIMALES - EAA LA PSICOLOGÍA DE LA EDUCACIÓN: un análisis fenomenológico}

\section{Jean Marlos Pinheiro Borba}

Doutor em Psicologia Social pela Universidade do Estado do Rio de Janeiro - UERJ. Professor do Departamento de Psicologia e do Programa de Pós-graduação em Psicologia Mestrado em Psicologia da Universidade Federal do Maranhão - UFMA. jean.marlos@ufma.br

Recebido para avaliação em 16/01/2017; Aceito para publicação em 31/10/2017.

\begin{abstract}
RESUMO
A Educação Assistida por Animais (EAA) é um tipo de Intervenção Assistida por Animais - IAA's utilizada no contexto escolar educacional com crianças e adolescentes inseridos no sistema educacional público ou privado de classes regulares ou especiais e têm seus resultados disseminados na literatura científica. O artigo tem como objetivo sistematizar e apresentar estudos e pesquisas que apontem as contribuições da Educação Assistida por Animais - EAA para a Psicologia da Educação. A pesquisa foi realizada utilizando a atitude e o método fenomenológico que orientaram a investigação para suspensão de hipóteses científicas e foco na atenção e na totalidade do que se apresentou à consciência intencional do pesquisador ao privilegiar o que aparece e como aparece. $\mathrm{O}$ universo da pesquisa constou da leitura selecionada de livros, artigos, periódicos, trabalhos de conclusão de curso, dissertações e tese de doutoramento. Após essa etapa foram descritas as contribuições dos autores acerca do uso de animais em atividades educacionais. Foram realizadas a localização, a leitura e a seleção de estudos e pesquisas que apresentaram contribuições, riscos e benefícios da EAA para problemas que emergem no contexto educativo. Os estudos foram sistematizados e indicaram que a EAA apresenta contribuições significativas não apenas à Psicologia da Educação, mas também para a Psicologia do Desenvolvimento, Educação Inclusiva, Psicomotricidade e Ética. Os resultados do presente artigo evidenciam os benefícios da relação humana e animal, tanto para os humanos quanto para os animais no contexto escolar dentro ou fora da sala de aula.
\end{abstract}

Palavras-chave: Intervenção Assistida por Animais - IAA; Psicologia; Educação; Animais; Humanos.

\section{ABSTRACT}

Assisted Education for Animals (EAA) is a type of Assisted Intervention for Animals (IAA) used in the educational context with school children and adolescents on public or private educational system of regular or special classes and have their results disseminated in scientific literature. The article aims to systematize and present studies and researches that show the contributions of

1 Artigo foi defendido e aprovado no curso de Pós-graduação em Psicologia da Educação da Universidade Estadual do Maranhão - UEMA sob orientação do prof. Dr. José Rômulo Travassos da Silva. 


\section{Dossiê: Diálogos interdisciplinares em Psicologia da Educação \\ | Contribuições da Educação Assistida por Animais - EAA para a Psicologia da Educação: uma análise fenomenológica|}

\section{|Jean Marlos Pinheiro Borba|}

Assisted Education for Animals - EAA Educational Psychology. The survey was conducted using the attitude and the phenomenological method guided the investigation for suspension of scientific hypotheses and focus on attention and all of what is presented to the intentional consciousness of the researcher focusing on what appears and as it appears. The research universe consisted of a set of books, articles, journals, term papers, dissertations and doctoral thesis were read selected. After this stage we described the contributions of the authors on the use of animals in educational activities. Location were carried out, as well as reading and selection of studies and surveys that submitted contributions, benefits and risks of EAA to problems that emerge in the educational context. The studies were systematized and indicated that the EAA has significant contributions not only to the Psychology of Education, but also for the Psychology of Development, Inclusive Education, Psychomotricity and Ethics. The results of this article show the benefits of human and animal relationship, both for humans and for animals in the school context within or outside the classroom.

Keywords: Assisted Intervention for Animals - AIA; Psychology; Education; Animals; Humans.

\section{RESUMEN}

Educación Asistida por Animales - EAA es un tipo de Intervención Asistida para Animales IAA's que se utilizan en el contexto educativo con niños y adolescentes escolares en el sistema educativo público o privado de las clases regulares o especiales, y sus resultados diseminados en la literatura científica. El artículo tiene como objetivo sistematizar y presentar estudios e investigaciones actuales que muestran las contribuciones de Educación Asistida por Animales Psicología Educacional EAA. La encuesta se llevó a cabo utilizando la actitud y el método fenomenológico que orientaron la investigación para la suspensión de las hipótesis científicas y foco en la atención y todo lo que se presenta a la conciencia intencional del investigador se centrando en lo que parece y como aparece. El universo de la investigación consistió en una serie de libros, artículos, revistas, trabajos académicos, disertaciones y tesis doctoral se leyeron, fueron seleccionados. Después de esta etapa describimos las contribuciones de los autores en el uso de animales en las actividades educativas. Se llevaron a cabo la ubicación, la lectura y la selección de los estudios y encuestas que presentaron contribuciones, beneficios y riesgos de EAA a los problemas que surgen en el contexto educativo. Los estudios fueron sistematizados e indicaron que la EAA tiene importantes contribuciones no sólo a la Psicología de la Educación, sino también para la Psicología del Desarrollo, Educación Inclusiva, Psicomotricidad y Ética. Los resultados de este artículo muestran los beneficios de la relación humana y animal, tanto para humanos como para animales en el contexto de la escuela dentro o fuera de la clase.

Palabras clave: Intervención Asistida por Animales - IAA; Psicología; La Educación; Animales; Humano.

\section{INTRODUÇÃO}

Este artigo apresenta algumas contribuições das Intervenções Assistidas por Animais - IAA's, mais especificamente da Educação Assistida por Animais - EAA e da Atividade Assistida por Animais - AAA’s para a Psicologia da Educação. Como objetivo secundário visa contribuir com os rumos da Psicologia e da Educação apresentando uma alternativa de atuação que tem se tornado uma prática mundial e nacional com resultados cientificamente reconhecidos. Pretende também, disseminar conhecimento para que os estudos e as práticas de IAA's, sobretudo de EAA e AAA possam ser agentes na promoção do ensino e da aprendizagem, melhorando o vínculo entre animais e humanos. Destaco 


\section{Dossiê: Diálogos interdisciplinares em Psicologia da Educação \\ | Contribuições da Educação Assistida por Animais - EAA para a Psicologia da Educação: uma análise fenomenológica|}

\section{|Jean Marlos Pinheiro Borba|}

que a recolocação do lugar do animal, enquanto ser vivo, dotado de capacidade empática (BELLO, 2006) e não apenas de um objeto da ciência natural, como tem sido mantido na história da humanidade.

Neste texto, promovo diálogo com saberes alternativos em Psicologia da Educação, tais como: behaviorista, construtivista e cognitivo comportamental fazendo uma fenomenologia dos estudos e práticas sobre as Intervenções Assistidas por Animais IAA's que são um tipo de prática interventiva multidisciplinar, tanto no que diz respeito à possibilidade de atuação de profissionais de diferentes formações, quanto de matrizes epistemológicas, teóricas e metodológicas diferentes. A Educação Assistida por Animais EAA's e as Atividades Assistidas por Animais - AAA's com seus olhares multidisciplinares e pluridisciplinares contemplam diferentes modos de atuar e fundamentar a prática terapêutica e educativa mediada por animais por reunir uma diversidade de possibilidades e contribuições de teorias e metodologias, sendo o Psicólogo e o Professor, dois destes profissionais.

A Psicologia da Educação é uma das atribuições do Psicólogo 2 e, para tratar destas atribuições, o Conselho Federal de Psicologia encaminhou em 17 de outubro de 1992 ao Ministério do Trabalho contribuições para integrar o Catálogo Brasileiro de Ocupações. Esta área é, enquanto uma atribuição do psicólogo, um campo de saber múltiplo que dialoga com diferentes abordagens teóricas, metodológicas e epistemológicas, sendo a pluralidade sua essência.

A vivência como psicólogo clínico e social também corroborou significativamente para que teoria e prática pudessem se fazer presentes nas minhas reflexões durante todo o curso de pós-graduação. Na vivência clínica, a atividade de inclusão de gatos e cães domesticados no atendimento de pessoas com sofrimento existencial oportunizou pensar que as Intervenções Assistidas por Animais - IAA's é uma possibilidade de avaliação e intervenção viável com resultados e contribuições concretas para a Psicologia e para a Educação, desde que o profissional esteja habilitado afetivamente, vivencialmente e com preparo teórico metodológico, para avaliar e intervir. Durante a pesquisa inicial, foram localizados os trabalhos de Godoy e Denzin (2007), Mascarenhas (2010), Lopes, Garcia e Santini (2013), Martins, Balbini e Stanquini (2014), Abrahão e Carvalho (2015) e Petenucci (2016) que apresentam teorização e relatos de experiências de atividades envolvendo animais no contexto educacional.

${ }^{2}$ Conferir no site: $<$ http://cfp.org.br/wp-content/uploads/2008/08/atr prof psicologo.pdf $>$. 


\section{Dossiê: Diálogos interdisciplinares em Psicologia da Educação \\ | Contribuições da Educação Assistida por Animais - EAA para a Psicologia da Educação: uma análise fenomenológica|}

\section{|Jean Marlos Pinheiro Borba|}

Busquei, assim, convergir interesses e estudos em Psicologia da Educação e Fenomenologia da Educação e da Aprendizagem aos estudos sobre IAA's. Na busca pelo aprofundamento, participei de três dos Simpósios Internacionais de Terapia, Educação e Atividades Assistidas por Animais - SINTAA's. A participação foi determinante para conhecer experiências e estudos nacionais e internacionais envolvendo IAA's, bem como apresentei comunicações orais e pôsteres com resultados de estudos e intervenções realizadas.

Após o levantamento realizado em compêndios e livros de história e introdução à Psicologia, como também de Psicologia da Educação, não foi localizado registro de estudo que evidencie e valorize a relação e o vínculo entre homens e animais, a não ser para usufruto científico por parte dos primeiros, no sentido de comprovar a validação de alguma teoria com foco sobre o comportamento humano, como, por exemplo, o behaviorismo. Em nenhuma das obras investigadas, as IAA's faziam parte de seus objetivos, mas sim, apresentavam teorias psicológicas e nuances históricas, teóricas e metodológicas nelas envolvidas.

Dentre estes teóricos, localizei F. B. Skinner (1990-1904) e L. Vygotsky (1896-1934) que se destacam por realizarem algum tipo de estudo e/ou experimentos para validar suas teorias. Nessas teorias, os animais não passam de objetos de estudo para confirmação teórica e poucos créditos são dados à sua importância no desenvolvimento infantil. Eis que, com o advento das IAA's, essa situação passa a ser repensada visto que nas intervenções os animais assumem o lugar de colaboradores e não de objetos ou recursos terapêuticos.

É importante ressaltar que os animais, ao lado do homem, sempre foram protagonistas na história da humanidade, quer do ponto de vista de uma Psicologia evolutiva, quer do ponto de vista de uma história ou Psicologia. Sempre foram encontrados registros na literatura da presença do animal na história da humanidade, estejam eles na qualidade de animais de companhia, caçadores, predadores ou infelizmente serviçais dos humanos.

$\mathrm{Na}$ contramão do uso de animais como recursos ou objetos, a médica psiquiatra alagoana Nise da Silveira foi pioneira na construção de vínculos com os pacientes psiquiátricos do Hospital Pedro $\mathrm{II}^{3}$ no Rio de Janeiro, tal atitude foi uma alternativa que aliava o trabalho no ateliê de pintura que foi improvisado no setor de terapia ocupacional do referido hospital (MELLO, 2015). Neste espaço, Nise e os seus colaboradores

\footnotetext{
${ }^{3}$ Em abril de 2017 tive a oportunidade de visitar o hospital e conhecer o Museu de Imagens do Inconsciente, local onde hoje estão expostas as obras de Nise, as pinturas e os desenhos dos paciente psiquiátricos. Conheci também a Biblioteca de Nise da Silveira que foi reproduzida dentro do museu com todos os livros e obras de arte da psiquiatra e dentro dela várias obras sobre gatos e mandalas. Ambas paixões de Nise.
} 


\section{Dossiê: Diálogos interdisciplinares em Psicologia da Educação \\ | Contribuições da Educação Assistida por Animais - EAA para a Psicologia da Educação: uma análise fenomenológica|}

\section{|Jean Marlos Pinheiro Borba |}

(auxiliares da enfermagem e um artista plástico) ligaram a arte e o convívio com animais para acessar o vivido de cada paciente com sofrimento psíquico grave. Nise se colocou contrariamente à perspectiva científica do uso de lobotomia e choques elétricos para tratar pacientes psiquiátricos e ofereceu a terapia ocupacional por meio do ateliê de pintura, permitindo aos pacientes o convívio com animais que transitavam dentro do ateliê, mesmo a contragosto da direção do hospital. Conforme Dotti (2014), os resultados observados possibilitaram que os animais deixassem de ser vistos apenas como animais de guarda e companhia, para assumir o lugar de coterapeutas. Nesse sentido, Martins, Balbini e Stanquini (2014) ao apresentarem resultados de experiências com animais utilizam o termo zooterapeutas.

A pesquisa desenvolvida se justifica pelas seguintes razões: a primeira, é a urgência e a relevância de ampliar investigações de cunho qualitativo e fenomenológico no cenário das pesquisas em Psicologia da Educação; a segunda, é a razão que se refere ao alcance e ao caráter inovador que as Intervenções Assistidas por Animais - IAA's têm alcançado no cenário mundial e brasileiro; a terceira, é possibilitar que psicólogos, professores, coordenadores pedagógicos, diretores e supervisores de instituições educacionais possam ter acesso ao resultado da presente investigação, como uma forma de devolução à sociedade pelo investimento feito por esta, através da Universidade Estadual do Maranhão - UEMA, em minha formação pessoal, acadêmica e profissional, que será feita por meio de publicação, palestras e apresentação de comunicações orais em eventos.

Desde 2011 tenho atuado como Psicólogo voluntário no Centro de Obras Sociais Frei Antônio Sinibaldi - COSFAS, instituição onde foram realizadas ações psicoeducativas com crianças, duas delas, com a intenção de promover o bem-estar animal: a) a primeira ação foi a execução da peça o Tribunal dos Bichos pelas crianças em 2011 e, b) a segunda, em 2015, uma roda de leitura e discussão de quadrinhos, orientações e leitura de um poema que possibilitou às crianças lerem e pensarem sobre suas experiências com animais, discutindo com os mediadores (psicólogo e estudante de Psicologia) suas opiniões acerca da relação homem-animal. O resultado dessa ação foi apresentado no formato de pôster eletrônico no II Simpósio Internacional de Atividades, Terapia e Educação Assistida por Animais - SINTAA intitulado "O gato não é ingrato? Relato de uma curta experiência de "sucesso" e "fracasso" com crianças alfabetizadas". É pretensão futura deste trabalho, a realização de vivências e atividades pedagógicas e de leituras com crianças que apresentam alguma dificuldade de socialização, de aprendizagem ou mesmo atraso no desenvolvimento da oralidade e da escrita para verificação in loco dos benefícios apresentados por diferentes 


\section{Dossiê: Diálogos interdisciplinares em Psicologia da Educação \\ | Contribuições da Educação Assistida por Animais - EAA para a Psicologia da Educação: uma análise fenomenológica|}

\section{|Jean Marlos Pinheiro Borba|}

autores. Penso que os conhecimentos adquiridos permitirão repensar o modo como as teorias que dão suporte às ações educativas possam vir a ser "aplicadas" no cenário educacional, principalmente quando associadas às contribuições das IAAs, já que estas teorias também estão presentes e fundamentam as intervenções. Ratifico, ainda, a necessidade que os educadores não tornem atividades com propósitos educativos em ações especistas que promovam maus-tratos.

\section{METODOLOGIA DA PESQUISA}

A metodologia utilizada nessa investigação foi predominantemente qualitativa, pois, não se debruçou sobre análise de variáveis, nem tampouco na atitude científico espiritual natural que busca mensurar e realizar estudos comparativos promovendo a naturalização e a matematização dos fenômenos. Ao contrário, o caminho seguido foi a orientação fenomenológica de investigação. Nesse sentido, fica suspenso, temporariamente, hipótese ou conclusão científica ou metodológica prévia. Por isso, busquei conhecer a produção existente sobre EAA, AAA, IAA, evidenciando contribuições para a Psicologia da Educação.

$\mathrm{Na}$ escrita deste optei por contemplar pesquisa e discussão dos resultados durante o texto e não, apenas, em sua parte final, tal como é feito no modelo científico tradicional. $\mathrm{Na}$ pesquisa de cunho fenomenológico, as evidências são apresentadas e discutidas na medida em que surgem: "trata-se de um movimento intelectual e ético do ser humano; trata-se da disponibilidade para procurar, e da disponibilidade para aceitar aquilo que se apresenta, e este é um caminho árduo" (BELLO, 2008, p. 80). Assim, seguindo a taxonomia de Vergara (1998), a pesquisa foi realizada quanto aos fins de modo exploratório e descritivo. Exploratória por não existirem trabalhos científicos que sistematizem estudos de EAA e apontem as contribuições desta para a Psicologia da Educação contemporânea. Descritiva, pois busquei a descrição de achados na literatura brasileira e internacional que apresentassem relatos de pesquisas, atividades de extensão e voluntariado nas quais ocorra interação entre homem-animal. Quanto aos meios, realizei um levantamento bibliográfico, documental e no meio virtual objetivando sistematizar estudos sobre Intervenções Assistidas por Animais - IAA's que tinham foco no processo educativo e de aprendizagem.

A atitude e o método fenomenológico, ambos de rigor, por ser um procedimento não experimental e a priorístico. Assim, pela análise fenomenológica não se busca constatação ou validação de teorias, mas, ao contrário, o pesquisador se lança na direção de 
|Jean Marlos Pinheiro Borba|

conhecer, compreender, descrever e evidenciar os fenômenos, da forma como eles se apresentam à consciência intencional do pesquisador (HUSSERL, 2006; 2012).

Após levantamento do material foi feita: a) seleção e agrupamento dos estudos sobre EAA/AAA; b) identificação das teorias e teóricos utilizados nos estudos; c) descrição dos tipos de animais e atividades desenvolvidas para promoção da aprendizagem; d) identificação das dificuldades de aprendizagem ou transtornos retratados e resultados observados; e) redação com a essência da pesquisa e apresentação rigorosa dos resultados obtidos; f) reflexão sobre as contribuições das IAA's, preferencialmente da AAA e da EAA para a Psicologia da Educação.

\section{PENSANDO A RELAÇÃO ENTRE A PSICOLOGIA, OS ANIMAIS E A EDUCAÇÃO NO MUNDO DA VIDA CONTEMPORÂNEA}

\begin{abstract}
"Os gatos são excelentes companheiros de estudos, amam o silêncio e cultivam a concentração".
\end{abstract}

Nise da Silveira

Ao pensar a relação entre os animais e a Psicologia, o pesquisador é lançado a um universo de referências, principalmente em um curso de graduação em Psicologia, com livros cujas imagens mostram cães, pombos e ratos submetidos aos experimentos de privação de liberdade, sede, fome por meio do condicionamento clássico. Nestes livros, por exemplo, em Marx e Hillix (1978) é comum que os cães, os gatos e os macacos fossem ligados a máquinas e outros com cérebros cortados para realização de experiências.

A leitura destes experimentos e os estudos sobre Intervenções Assistidas com Animais - IAA permitiu-me compreender que a lógica científica tradicional prima por matar animais ou submetê-los a condições de estresse em prol dos seus interesses, tendo como referência procedimentos autorizados por Comitês de Ética em Pesquisa. De outro lado, Greif (2003), Singer (2010) e Susin e Zampieri (2013) desenvolvem argumentos contra a pesquisa científica e o comércio de animais para atender aos interesses da ciência e do mercado, respectivamente, retirando-lhes a liberdade e o direito de viver com iguais, tal como ocorre com muitos animais domesticados. Menezes Filho e Gurgel (2011) e Singer (2013) também corroboram com argumentos contrários à perspectiva dominante do uso de animais legitimarem as atividades científicas, tal como ocorre nas pesquisas experimentais fruto do especismo. 
Dossiê: Diálogos interdisciplinares em Psicologia da Educação

| Contribuições da Educação Assistida por Animais - EAA para a Psicologia da Educação: uma análise fenomenológica|

\section{|Jean Marlos Pinheiro Borba|}

É de conhecimento de todos que, em Psicologia, fomos historicamente apresentados a um modo de conhecer o homem que sempre era justificado pelo conhecimento das ações do animal, ou seja, pela observação do comportamento do animal, chegaríamos, pela via da generalização, a conclusões sobre os modos de se comportar do homem. Essa escola de pensamento ficou conhecida por behaviorismo e foi responsável pela inclusão da psicologia no cenário científico, mais especificamente de uma ciência do comportamento. O paradigma impresso pelo behaviorismo refere ser possível explicar o comportamento humano por meio da observação e experimentação sistemática com rigor da ciência natural, já que este modo de fazer psicologia deixou para trás a definição de ciência da alma e de ciência pura da consciência (CARPIGIANI, 2010).

Utilizar animais para compreender, manejar e controlar o comportamento do homem encontra respaldo nos fundamentos do behaviorismo, que sustenta seus argumentos centrais no positivismo lógico (RICHARDSON, 1999). Fundamentos estes que, infelizmente, colocaram o homem como ser dominante da natureza e no "direito" de utilizar o animal para fins científicos. Os interesses da ciência experimental, que também alcançaram a Psicologia, foram logo capturados pelos sistemas econômicos, sendo que tais interesses contribuíram progressivamente para o sofrimento de inúmeros animais, sob o jargão de uma ética, e também para o desenvolvimento técnico e científico, fortemente marcado por empresas capitalistas de diferentes segmentos que têm forte interesse no uso do animal para o benefício de suas pesquisas, a saber: a indústria farmacêutica, de cosméticos e de alimentos.

Apesar deste cenário, surgiram ao longo dos anos, vários atores quer do segmento da proteção animal, quer da própria ciência ou sociedade que direcionaram seus esforços, exigindo a interrupção dos maus-tratos e uso de animais em experimentos científicos, por quaisquer que sejam as razões. Ainda há um longo caminho a percorrer, todavia já é possível sentir uma mudança na postura de tratamento dos animais no mundo da vida contemporânea. Mundo da vida é o termo utilizado por Husserl (2012) e referenciado por Guimarães (2012) e Borba (2015) para se referirem ao mundo no qual a vida não se desvincula dele, ou seja, não pode haver na perspectiva fenomenológica mundo sem vida. Logo, qualquer prática experimental que coloque a vida de um animal em risco, privação de liberdade, violência por retirá-lo do seu habitat natural e convívio com outros animais, fome, sede, ou mesmo como técnica, não representa o respeito à alteridade, à empatia e animalidade do animal. 


\section{Dossiê: Diálogos interdisciplinares em Psicologia da Educação \\ | Contribuições da Educação Assistida por Animais - EAA para a Psicologia da Educação: uma análise fenomenológica|}

\section{|Jean Marlos Pinheiro Borba|}

Atualmente, muitos movimentos, em nome da liberdade animal, têm tomado maior espaço e exigido, inclusive da comunidade científica, ações que excluam de seu meio o uso de animais em experimentos (SINGER, 2013). Já existe, por exemplo, no mercado um programa de computador denominado o Rato Sniff ${ }^{4}$ que possibilita simulações dos experimentos realizados pelos analistas do comportamento, para transmitir os conhecimentos sobre psicologia experimental e behaviorismo clássico a discentes de curso de Psicologia, apesar de muitos ainda continuarem a professar esta prática de maus-tratos, sob o jugo da ciência.

O efetivo uso desta tecnologia diminuiria consideravelmente os efeitos causados aos animais de laboratório, dentre eles, o estresse, o isolamento e a retirada de seu ambiente natural para fins exclusivos de pesquisa. Mas, contrapondo-se a toda essa perspectiva experimentalista, a fenomenologia se insurge desde os anos de 1900-1901 com Edmund Husserl (1859-1938), quando inicia seus estudos e críticas ao pensamento lógicomatemático e ao naturalismo e seu aspecto doutrinador (HUSSERL, 1965; 2009).

Em "Investigações Lógicas: prolegômenos à Lógica Pura" (1900-1901/2014), Husserl estabelece em suas análises as razões pelas quais a atitude natural científica, pautada no naturalismo e no psicologismo fundamentaram as ciências, dentre elas a Psicologia. A Psicologia foi fortemente influenciada pela ciência natural, tornando-se como bem lembra Husserl (1911/2009) uma ciência natural da consciência e uma ciência que visa a economia do pensar, como fruto de pesquisas abstratas realizadas pela psicologia (HUSSERL, 2014). Esse procedimento visa a uma redução das vivências, ou seja, minimizando-as, tornando-as objetificáveis por meio de um olhar técnico, e não uma redução no sentido fenomenológico, ou seja, o de reconduzir - do alemão, reduktion -, conforme Goto (2008), ao sentido originário do vivido, fazendo, assim, uma Fenomenologia da consciência (HUSSERL, 2009).

É com base nestes fundamentos fenomenológicos e compreendendo que não é a partir do animal que se interpreta o homem ou se explica o seu comportamento, mas, numa perspectiva fenomenológica, que a relação do homem se estabelece com este animal, evidenciando os sentidos e os significados vivenciados nestas relações diante do mundo da vida. No caso da educação, da leitura e das atividades assistidas, o animal atua como facilitador de acesso do estudante ao vivido e ao convívio social, permitindo que a aprendizagem seja facilitada pela interação.

\footnotetext{
${ }^{4}$ Sniffy - O Rato Virtual - Versão 2.0, informações disponíveis em: < http://www.cengage.com.br/ls/sniffy-
} o-rato-virtual-versao-2-0/>. 


\section{AS INTERVENÇÕES ASSISTIDAS POR ANIMAIS - IAA's}

As Intervenções Assistidas por Animais - IAA's é o termo "guarda-chuva" que utilizamos para o conjunto de intervenções nas quais o animal exerce papel central. São tipos de intervenções: a Terapias Assistidas por Animais - TAA, as Atividades Assistidas por Animais - AAA e a Leitura Assistida por Animais - LAA, que também é considerada um tipo de AAA. As IAA também podem ser encontradas com os seguintes nomes Zooterapia, Pet terapia, Piterapia (terapia com cães da raça Pitbull), cinoterapia (terapia com cães de qualquer raça), equoterapia (terapia com cavalos) e dolphinterapia (terapia com golfinhos, do inglês Dolphin) (DOTTI, 2014).

Medeiros e Dias (2003), Lermontov (2004), Capote e Costa (2011), Dillon (2013), Dotti (2014) e Petenucci (2016) são alguns dos autores que publicaram livros que selecionamos para compor o universo desta investigação. Soma-se a isso um significativo conjunto de artigos publicados em periódicos que estão sendo, por força da metodologia adotada, coletados, organizados, lidos e sistematizados para compor essa investigação. Cada autor, a seu modo, apresenta as intervenções com animais como alternativas para os métodos tradicionais de terapia, atividades integradoras e socioeducativas.

No Brasil, créditos são atribuídos a Nise da Silveira ${ }^{5}$, médica psiquiatra de fundamentação junguiana, que se negou a aplicar eletrochoques em seus pacientes diagnosticados com esquizofrenia e passou a utilizar animais no relacionamento com os pacientes de sua responsabilidade, em 1955, no hospital psiquiátrico da Praia Vermelha, na Cidade do Rio de Janeiro.

A recusa da psiquiatra ocasionou um incômodo na classe médica que, só posteriormente, reconheceu o seu método de trabalho. Nise da Silveira se tornou modelo de alternativa metodológica no trato com pacientes em hospital psiquiátrico, assim como, serviu de inspiração para inúmeros projetos em instituições asilares, hospitalares, presídios e escolas (DOT'TI, 2014).

Dotti (2014) e muitos outros autores argumentam que Dra. Nise observou em suas atividades que o contato do animal, coterapeuta, com os pacientes psiquiátricos produzia resultados excelentes. Essa experiência foi recentemente transformada em filme, com o título "Nise: O coração da Loucura" exibido nas salas de cinema brasileiro. O autor relata ainda que na França já se utilizava cães, gatos, peixes e pássaros como terapeutas nos hospitais franceses.

5 Informações sobre vida e obra de Nise da Silveira podem ser obtidas no site: $<\underline{\text { http://www.ccms.saude.gov.br/nisedasilveira/index.php }>\text {. }}$ 


\title{
Dossiê: Diálogos interdisciplinares em Psicologia da Educação \\ | Contribuições da Educação Assistida por Animais - EAA para a Psicologia da Educação: uma análise fenomenológica|
}

\section{|Jean Marlos Pinheiro Borba|}

Petenucci (2016) destaca que tratar de intervenções com animais no ambiente educacional já é uma prática que tem sido pesquisada e realizada dentro e fora da escola quer com crianças, quer com adolescentes ou adultos. Ressalta a autora que são os jogos e a leitura algumas das atividades educativas que têm sido utilizadas por profissionais de diferentes formações. Acrescenta, ainda, que o cão e o cavalo figuram como os animais mais utilizados nas atividades de intervenção.

\section{A Educação Assistida por Animais - EAA}

A EAA é um tipo de IAA’s sendo considerada por Petenucci (2016, p. 298) como:

\begin{abstract}
[...] uma ação pedagógica ampla que envolve a utilização de animais em todo cenário educacional e com diversos públicos. Ela pode utilizar cães, cavalos e outros animais no atendimento de crianças com ou sem necessidades especiais, na pedagogia hospitalar ou na andragogia - área da educação que se ocupa do processo ensino-aprendizagem de adultos. A EAA visa difundir a utilização dos animais como recursos pedagógicos. Sendo assim, ela é a utilização dos animais nas interações pedagógicas, em um cenário educacional que pode ser dentro ou fora da escola e pode ser voltada para todas as idades.
\end{abstract}

A EAA está contida nas Intervenções Assistidas por Animais - IAA, de acordo com Petenucci (2016), todavia, na medida em que, mais atividades com caráter eminentemente pedagógico e educativo vão sendo realizadas, a EAA começa a ser separada da TAA e da AAA, visto que ela passa a ter respaldo teórico e metodológico das abordagens que orientam a sua prática. As atividades envolvendo animais permitem ganhos significativos imediatos, tanto no que diz respeito à interação, ao interesse e a quebra de barreiras e dificuldades para aprender ou ler, por exemplo. O objetivo principal da EAA, como destacam Abrahão e Carvalho (2015, p. 1): “é promover a aprendizagem estimulando o desenvolvimento psicomotor e psicossocial".

Dotti (2014), ao tratar da relação entre os animais e os humanos, destaca que tanto com as crianças quanto com os idosos os animais sempre estiveram presentes em suas vidas, seja como companhia, seja como guarda ou até mesmo como personagens de histórias e vivências. $\mathrm{O}$ autor destaca que há cumplicidade entre crianças e animais, uma vez que os animais já fazem parte do cotidiano das famílias. Nessa perspectiva, a EAA pode ser realizada de diferentes maneiras e, assim sendo, estão incluídas atividades de leitura, jogos e brincadeiras. Nas atividades de leitura, a criança lê na presença do animal ou para o animal, atividade esta também que pode ser utilizada em instituições educacionais, hospitalares, comunidades terapêuticas, asilos ou presídios. 


\section{Dossiê: Diálogos interdisciplinares em Psicologia da Educação \\ | Contribuições da Educação Assistida por Animais - EAA para a Psicologia da Educação: uma análise fenomenológica|}

\section{|Jean Marlos Pinheiro Borba |}

O foco da EAA é que define como as atividades serão implantadas, avaliadas e reestruturadas, e, ainda, qual animal é mais adequado e em que circunstância a sua inserção como coeducador ou coterapeuta deve ser iniciada. As AAA e EAA podem alcançar um foco amplo de atuação e alcance social, não apenas por atender a um público-alvo das intervenções, mas, também, por ressignificar a relação homem-animal, podendo contribuir consideravelmente para a mudança da visão tecnicista e especifista que tem acometido nessa relação. A exemplo disso, Greif (2003) destaca o uso prejudicial e inadequado de animais no ensino universitário, ao uso naturalizado dos animais em experimentos científicos e muitas vezes apoiados em teorias pedagógicas e psicológicas que são utilizadas para promover a dissecação, a dessensibilização e a vivissecção dos animais em nome da "Ciência" e do bem-estar humano, apenas. Nesse sentido, todos esses procedimentos devem ser questionados rigorosamente.

É importante destacar, também, que o autor dá ênfase que os estudantes universitários são os primeiros a passarem pelo procedimento de dessensibilização com o propósito de não se sentirem culpados ou responsáveis pela morte do animal. Ao contrário disso, as Intervenções Assistidas por Animais - IAA tornam-se uma alternativa na qual, ao contrário dos procedimentos experimentais, os animais são assunto e lugar central da relação homem-animal, não como objetos, mas, como atores do processo, quer seja como coterapeutas ou coeducadores.

$\mathrm{Na}$ direção de também pensar uma prática educativa longe de uma ética utilitária e pautada num especificismo, Menezes Filho e Gurgel (2015) discutem a questão da ética e da experimentação animal, problematizando a tensa relação científica que existe no uso de animais em experimentos, inclusive, experimentos para validação teórica. Nessa linha de pensamento, encontramos Singer (2010) que traça um panorama das relações homem versus animal e do modo como o sistema capitalista e a ciência se apropria do animal.

Em geral, os autores evidenciam a apropriação inadequada, os prejuízos ambientais, a naturalização das ações acadêmicas para com o uso de animais e também a colocação do especifismo como a definição de que o humano se dá o direito de escolher qual animal deve morrer em nome da ciência. Uma questão não apenas ética, mas de ordem cultural e abraçada pela legislação. $\mathrm{Na}$ contramão do uso de animais em experimentos e por respeito aos mesmos, ao longo de anos várias legislações foram surgindo. Entretanto, muitas delas, como a Lei $\mathrm{n}^{\circ} 10.169$, de 5 de dezembro de 2014, vigente no estado do Maranhão, apesar de significar um avanço ainda é extremamente tendenciosa e não representa uma mudança significativa na relação de respeito, proteção e cuidados com os animais. 


\section{Dossiê: Diálogos interdisciplinares em Psicologia da Educação \\ | Contribuições da Educação Assistida por Animais - EAA para a Psicologia da Educação: uma análise fenomenológica|}

\section{|Jean Marlos Pinheiro Borba|}

Conforme destaca Petenucci (2016), o movimento de EAA no Brasil ainda é recente, mas, mesmo assim, já é possível localizar experiências com uso de animais em atividades educativas e de leitura. Destaca a autora que as escolas não têm conseguido o sucesso desejado para promover o aprendizado e minimizar os efeitos das dificuldades de aprendizagem.

Os estudos sobre dificuldades de aprendizagem - learning disability -, segundo Barbosa (2015), tiveram origem com os estudos do psicólogo Samuel Kirk, o qual desenvolveu a tese de que alunos com os quais tinha contato apresentavam déficits intelectuais, na escrita e na leitura. A partir desses estudos, o termo passou a ser utilizado por profissionais da área médica e, posteriormente, educacional sendo incorporado mais tarde à Psicopedagogia. A autora apresenta ainda os registros das dificuldades frequentemente observadas e as bases teórico-metodológicas de sua existência. O certo é que o uso do termo dificuldade de aprendizagem se, por um lado, foi aceito e tornou-se inquestionável, por outro, mobilizou profissionais da educação e da psicologia para repensar a naturalização das dificuldades e a emergência da medicalização da vida e da educação.

Nesse sentido, seguindo a orientação fenomenológica, defendo a tese de que ao entrar em contato com o aluno, o professor e a equipe pedagógica devem focar seus olhares para a pessoa em situação de aprendizagem e não para o transtorno ou para a dificuldade. Tal fato se tornou extremamente difícil, ocasionando a identificação, colocação de rótulos e a medicalização de crianças como, por exemplo, nos transtornos de déficit de aprendizagem e/ou hiperatividade - TDHA (BORBA, 2015).

O animal no lugar de coterapeuta estabelece o vínculo imediato com a criança, porque não vê o transtorno, nem a criança com dificuldade. Isso possibilita o acesso ao mundo vivido pela criança e a compreensão do que ocorre com ela (BORBA, 2015). Nesse sentido, a EAA pode ser uma alternativa viável para lidar com as DA. Abrahão e Carvalho (2015) ao tratarem da relação homem-animal no ambiente educacional ratificam que eles podem ser chamados de coterapeutas ou coeducadores exatamente por assistirem humanos em atividades com outros humanos. Destaca, ainda, que há muitos benefícios na interação de humanos com animais, dentre eles, a melhora de ordem psicológica e emocional.

Os estudos existentes sobre TAA, IAA e EAA apresentam alternativas para a parceria entre homem e o animal, no sentido de promover ações que melhorem a qualidade de vida dos humanos e dos animais. Estas ações devem ser rigorosas, a fim de promover o respeito aos direitos dos animais e sua condição de ser senciente. A equoterapia é 
Dossiê: Diálogos interdisciplinares em Psicologia da Educação

| Contribuições da Educação Assistida por Animais - EAA para a Psicologia da Educação: uma análise fenomenológica|

\section{|Jean Marlos Pinheiro Borba|}

apresentada por Medeiros e Dias (2003) como alternativa terapêutica para distúrbios de aprendizagem. Lermontov (2004) destaca também de que maneira atividades desenvolvidas com cavalos podem ser utilizadas com crianças para desenvolver seu equilíbrio intelectual e motor por meio de atividades psicomotoras. Nesses estudos, as autoras afirmam os benefícios, as vantagens, os cuidados e os riscos da utilização de cavalos.

No Brasil, os cavalos por meio da equoterapia têm sido os animais mais utilizados para tratamentos e atividades socioeducativas, fato que levou as atividades desenvolvidas pelos centros de equoterapia credenciados à Associação Nacional de Equoterapia ANDE $^{6}$ serem reconhecidas pelo Conselho Federal de Medicina - CFM (6 de abril de 1997), pelo Conselho Federal de Fisioterapia e Terapia Ocupacional - COFFITO (27 de março de 2008) e pela Secretaria de Educação do Distrito Federal - SEDF.

Capote e Costa (2011) destacam de que modo a TAA pode ser um instrumento que possibilite o desenvolvimento psicomotor de crianças com deficiência intelectual. A leitura, a atividade de contar histórias e as brincadeiras envolvendo cães, gatos e outros animais também merecem destaque nas AAA e EAA, uma vez que elas representam uma alternativa ética e adequada de "utilização" dos animais, desde que sejam seguidos critérios para seu bem-estar e bons tratos.

Huizinga (1999, p. 3 apud PORTO, 2015, p. 11) confirma que a criança vive em estado de jogo: "O homo ludens tem sua melhor expressão e mais plena vigência na idade infantil. A criança forma-se num processo de jogos, de interação lúdica com as outras pessoas, com os objetos, com os animais, com os fatos”. Então, se a criança vive em estado de jogo, conforme afirma Huizinga (1999), é certo que a relação entre homem-animal também é perpassada por brincadeiras e jogos, ou seja, há um aspecto lúdico presente na interação entre ambos que pode ser potencializada e ser objeto de intervenção com crianças, adultos e idosos, com ou sem dificuldades de interação social e/ou de aprendizagem. Dainty (2009) apresenta inúmeras brincadeiras que podem ser feitas com um cão que podem vir a ser utilizadas nas AAA ou na EAA, pois são essas brincadeiras e jogos que promovem a interação e trabalham aspectos psicomotores. As brincadeiras com cães e humanos, por exemplo, possibilitam também aos humanos ampliar suas relações sociais, logo, um simples passeio com um cachorro, tornou-se, no cenário contemporâneo motivo para encontros sociais entre donos de cães.

Mascarenhas (2010) afirma que as EAA e as AAA contribuem de maneira significativa para ampliar as possibilidades tanto de convivência quanto de aprendizagem.

\footnotetext{
${ }^{6}$ Sobre as atividades da ANDE, consultar:

< $\underline{\text { http://equoterapia.org.br/articles/index/article detail/140/2024 > }}$.
} 


\title{
Dossiê: Diálogos interdisciplinares em Psicologia da Educação \\ | Contribuições da Educação Assistida por Animais - EAA para a Psicologia da Educação: uma análise fenomenológica|
}

\section{|Jean Marlos Pinheiro Borba |}

Em suas teorizações, apresenta um estudo sobre o uso de animais em atividades de intervenção com crianças e destaca que ocorre, muitas vezes indevidamente, por parte de professores apontarem a indisciplina com problemas de comportamento, relatando os benefícios e as dificuldades encontradas, dentre os mais frequentes estão: hiperatividade, bullying, comportamento opositor/perturbação de oposição, perturbação de conduta, e agressividade. Tais problemas geralmente se manifestam nas interações, como por exemplo, durante jogos e brincadeiras. Porto (2015) demonstra que o brincar, a brincadeira e os jogos carregam em si inúmeros aspectos culturais. Possuem em si os mesmos traços das relações entre os povos, do lugar dos materiais, da estrutura hierárquica e de poder, das relações de gênero e também na aprendizagem.

Levinson (1962, apud COLOSIO, 2009, p. 12) em seu primeiro artigo "O cão como co-terapeuta" relata uma experiência entre o brincar e a psicoterapia como modo de acolher e acessar a criança:

\begin{abstract}
Uma criança trazida pelos pais por apresentar um aumentado grau de comprometimento tendo sido recomendada hospitalização; chegando ao consultório o cão se aproximou da criança e começou a lambê-lo e esse não demonstrou medo, mas sim começou acariciá-lo. Os pais queriam separar a criança do cão, porém foi aconselhado que deixassem a criança. Após algum tempo ali brincando, a criança perguntou se sempre o cão brincava com as crianças que vinham ao consultório. Tranquilizada diante da resposta, voltou a brincar com o cão. Por várias sessões a criança brincou com o cão ignorando totalmente a presença do terapeuta, gradualmente com um pouco de atenção eliciada pelo cão o terapeuta foi sendo incluso na brincadeira. Lentamente foi se estabelecendo um bom relacionamento de trabalho e a eventual reabilitação desta criança.
\end{abstract}

Como se pode observar, Levinson, segundo o levantamento realizado, foi o primeiro a utilizar animais como modo de interação com humanos em atividade de psicoterapia preferencialmente crianças. E, anos mais tarde, no Brasil, a psiquiatra Nise da Silveira, de acordo com Campos (2009). Ainda sobre o Levinson, este escreveu o livro intitulado "Psicoterapia infantil Assistida por Animais" e, segundo Colosio (2009), o terapeuta intitulou seu trabalho de Pet Therapy, ou seja, terapia com animal de estimação.

Nessa trajetória do brincar e do desenvolvimento lúdico, os animais estiveram lado a lado com os humanos, ora como objeto do brincar, ora como companheiros de jogos e brincadeiras. Em filmes de domínio público a que todos têm acesso, a equitação com cavalos, por exemplo, e os passeios em assíneos e/ou pôneis fizeram parte de atividades de crianças pertencentes às classes burguesas. Já os cães, gatos, peixes e pássaros e até mesmo galinhas compõem o cenário da brincadeira de crianças de classes baixas. Com a evolução do capitalismo, os animais passaram a ser utilizados como elementos da indústria cultural, 


\section{Dossiê: Diálogos interdisciplinares em Psicologia da Educação \\ | Contribuições da Educação Assistida por Animais - EAA para a Psicologia da Educação: uma análise fenomenológica|}

\section{|Jean Marlos Pinheiro Borba|}

quer do entretenimento, quer da leitura. Furta-nos a possibilidade de mensurar a quantidade de jogos e brincadeiras, desenhos animados nos quais os animais são utilizados como elementos lúdicos, de simples entretenimentos ou mesmo formadores de subjetividades (BORBA, 2015).

\section{CONTRIBUIÇÕES DAS IAA'S PARA A PSICOLOGIA DA EDUCAÇÃO}

O ambiente educacional possui uma convergência de fenômenos psicossociais, econômicos, socioculturais que são adequados para as práticas de IAA's. Tomando por base esse pressuposto, foram localizados os seguintes estudos que apresentam IAA's, preferencialmente da Educação Assistida por Animais - EAA como alternativas aos problemas humanos presentes no contexto educacional: Medeiros e Dias (2003), Lermontov (2004), Godoy e Denzin (2007), Roiffé (2009), Colosio (2009), Mascarenhas (2010), Capote e Costa (2011), Melo (2014), Dotti (2014), Abrahão e Carvalho (2015). Todos os autores pesquisados ratificam que as IAA's são adequadas para o trabalho com crianças.

Convém ressaltar que as IAA's não surgiram no cenário educacional como uma alternativa milagrosa, mas como um modo de contribuir para ampliar as possibilidades educativas, relacionais e cognitivas dos atores envolvidos. Roiffé (2009, p. 38) argumenta que a participação de animais em atividades educativas no cotidiano escolar favorece ao desenvolvimento intelectual, social e afetivo de vários alunos, independente do animal utilizado, uma vez que a interação com o animal aproxima da criança ou do adolescente os conteúdos que são objeto da aprendizagem.

As contribuições das IAA's, mais especificamente da EAA, não ficam limitadas apenas à Psicologia da Educação, mas estendem-se à Educação Inclusiva, à Psicomotricidade, à Psicologia do Desenvolvimento, Saúde Mental e à própria Ética, visto que o profissional condutor da atividade associa o possível resultado esperado às teorias e áreas multidisciplinares.

A interação crianças e animais no campo da educação, segundo relata Roiffé (2009), tem sido alvo de estudos brasileiros, dentre eles, merece destaque o: "Projeto como Dr. Escargot e Interações entre crianças e animais - algumas contribuições para a Psicologia do Desenvolvimento", da profa. Dra. Vanessa Breia da Faculdade de Formação de Professores da Universidade do Estado do Rio de Janeiro - UERJ. 
Dossiê: Diálogos interdisciplinares em Psicologia da Educação

| Contribuições da Educação Assistida por Animais - EAA para a Psicologia da Educação: uma análise fenomenológica|

\section{|Jean Marlos Pinheiro Borba|}

Nesse sentido, Mascarenhas (2010) aponta como principais benefícios das IAA: empatia, focalização externa, educação e afeto. Além disso, contribuições no desenvolvimento da comunicação, aceitação, entretenimento, socialização, estimulação mental, contato físico e toque, benefícios psicológicos e até espiritualidade.

\section{CONSIDERAÇÕES FINAIS}

As Intervenções Assistidas por Animais - IAA correspondem ao conjunto de práticas de Terapia Assistida por Animais - TAA, Atividades Assistidas por Animais AAA e a Educação Assistida por Animais - EAA. As AAA e a EAA, especialmente, com o auxílio de diferentes abordagens teórico-metodológicas podem contribuir de modo significativo para o processo educacional, tanto nas ações de ensino, quanto nas de aprendizagem, assim como elas se constituem como uma alternativa para lidar com as famosas "dificuldades" de aprendizagem e com a medicalização na educação.

Os remédios de quatro patas, os animais, têm ganhado espaço no cenário científico, cultural e educacional, deixando de ser meros "instrumentos" da ciência natural para serem coterapeutas. Na interface entre Psicologia e Educação, como, nas atividades de leitura assistida por animais, há grande possibilidade de contribuição advinda desta área. Muitas vivências compartilhadas por profissionais e assistidas pelo autor em eventos internacionais, mesmo não tendo sido aqui relatadas em função do espaço e objetivo, permitem apontar um novo caminho, apesar das dificuldades e cuidados que são exigidos nas IAA's.

O que se pretendeu com o trabalho foi sistematizar experiências e estudos, bem como apresentar as IAA's (EAA e AAA) como uma alternativa, e não torná-la uma técnica ou uma solução para os problemas educacionais ou psicossociais, de modo algum. Busquei apresentá-los como possibilidade enquanto prática com fundamentação teórica, metodológica e epistemológica consistente, e não um modismo. As IAA's se constituem como uma possibilidade por diferentes razões e, dentre elas, destaco: a) a primeira, e mais significativa, é o resgate da relação homem-animal-mundo-da-vida, retirando o animal do lugar de ser inferior ou simplesmente de objeto da ciência, visto ser ele o protagonista das intervenções; b) a segunda, a reflexão sobre ética, bem-estar animal e sobre o especifismo presente na ciência, que retira a liberdade do animal enquanto ser vivo e o coloca na condição de objeto de estudo científico, como aquele que, se necessário, deve morrer, claro que respaldado por uma legislação tendenciosa; c) a terceira, a EAA é uma prática já 
Dossiê: Diálogos interdisciplinares em Psicologia da Educação

| Contribuições da Educação Assistida por Animais - EAA para a Psicologia da Educação: uma análise fenomenológica|

\section{|Jean Marlos Pinheiro Borba|}

estudada e desenvolvida por diferentes profissionais, tendo seus usos associados, principalmente, às questões relacionadas a transtornos e dificuldades de aprendizagem como objetos de estudo da educação especial; d) a quarta, os animais mais utilizados são gatos, cães, peixes, escargots, cavalos e aves. Os animais são selecionados considerando o tipo de atividade proposta, o local e o vínculo que possa ser estabelecido entre a criança e o animal; e) A equoterapia tem sido uma prática terapêutica utilizada na área educacional, sendo reconhecida pelo Conselho Federal de Medicina e pelo Conselho Federal de Fisioterapia e Terapia Ocupacional; f) A EAA tem sido reconhecida como prática em algumas escolas públicas e particulares no Estado de São Paulo e Rio de Janeiro; g) O Conselho Federal de Psicologia - CFP já apoia, por meio de seus conselhos regionais, eventos que tratam da interação homem-animal, entretanto, ainda não há resolução interna que regularmente a intervenção com animais;

Atualmente no Brasil as seguintes instituições mantêm IAA's, como: Instituto para Atividades, Terapias e Educação Assistida por Animais de Campinas - ATEAC, Patas Therapeutas, Instituto Brasileiro de Educação e Terapia Assistida por Animais - IBETAA, Projeto Pêlo Próximo - Solidariedade Humanimais em 4 patas.

As instituições acima citadas têm, entre suas atividades, a EAA como um de seus modos de intervenção. Nesse sentido, convém relatarmos que o levantamento realizado pelo autor deste trabalho, foi realizado, inicialmente, por meio do Grupo de Estudos e Pesquisas em Fenomenologia e Psicologia Fenomenológica e, posteriormente, no Grupo de Estudos e Pesquisas em Saúde e Intervenções Assistidas por Animais - GEPS\&IAA’s. Atualmente, encontra-se em elaboração, um protocolo de intervenção e pesquisa para atuação em instituições educacionais, sociais e escolares.

A participação de alunos e profissionais da Psicologia e áreas afins tem sido relevante nas reuniões de estudo para conhecerem as IAA's e tornarem-se aptos e capacitados para atividades iniciais com IAA's. Nesse sentido, em março 2016 foi encaminhado pelo autor deste trabalho a proposta de criação do Grupo de Trabalho Psicologia e Intervenções Assistidas por Animais que tem como intenção reunir os profissionais de Psicologia e promover ações de orientação e fiscalização. Em 2017 o grupo iniciou oficialmente suas atividades, sendo o primeiro GT no país formado por psicólogos e estudantes de psicologia (como colaboradores) que têm discutido e planejado ações de orientação sob a tutela e apoio do Conselho Regional de Psicologia.

A metodologia utilizada neste artigo possibilitou conhecer, descrever, evidenciar e refletir tanto sobre a aprendizagem ocorrida no curso de Psicologia da Educação, a partir 
Dossiê: Diálogos interdisciplinares em Psicologia da Educação

| Contribuições da Educação Assistida por Animais - EAA para a Psicologia da Educação: uma análise fenomenológica|

\section{|Jean Marlos Pinheiro Borba|}

da reflexão da vivência do autor, característica da pesquisa fenomenológica, quanto da análise das referências sobre Educação Assistidas por Animais - EAA e Atividades Assistidas por Animais - AAA, tipos de Intervenções Assistidas por Animais - IAA's aqui evidenciadas como área de conhecimento em ascensão, que possibilitam associar práticas educativas com outras atividades.

Por fim, sintetizo, a seguir, o que a pesquisa permitiu compreender as principais contribuições que as IAA's podem ser oferecer para a Psicologia da Educação são elas:

a) A melhoria da socialização dentro e fora do ambiente escolar, melhora da depressão, da ansiedade e da solidão, desenvolvimento da concentração, motivação para a realização de atividades, inclusão, melhora na capacidade sensorial, motora e cognitiva, como defendem Martins, Balbini e Stanquini (2014); b) Penso que a relação entre humanos e animais envolve troca imediata de afeto, sendo o afeto um facilitador da aprendizagem, considerando que desde a infância as crianças mantêm algum tipo de relação com animais, seja no convívio direto, seja em histórias, filmes e desenhos animados e outros meios, ressalto que esse convívio pode ser potencializado para fins educacionais; c) Os animais têm sido utilizados principalmente com Portadores de Necessidades Especiais Educacionais - PNEE, mas há outras participações importantes como em atividades de leitura, que, nesse caso, passam a ser chamadas de Leitura Assistida por Animais - LAA ou mesmo em atividades em que se deseja avaliar o desenvolvimento psicomotor, a interação social e as habilidades sociais, como é o caso do estudo de Melo (2014); d) Nos estudos levantados, constantes nas referências deste artigo, os pensadores citados como referências de base para o trabalho com crianças e animais estão: Celestin Freinet, Paulo Freire, Madalena Freire, Lev Vygostky, Ovide Decroly, A N. Leontiev, Henri Wallon, Boris Levinson e Nise da Silveira.

Defendo que o uso de animais no ambiente educacional ou fora dele pode contribuir para que crianças e adolescentes vivenciem, na prática, situações problemas que ocorrem na vida fora da escola, tais como: aprender a lidar com preconceitos, diferenças sexuais, liberdade e responsabilidade, interação social, aumento da autoestima e segurança, diminuição da ansiedade, concentração e melhoria da leitura, deficiências e limitações físicas, psicomotoras e intelectuais etc. Defesa observada nos autores referenciados neste artigo.

Compreendo, após a realização deste estudo, que a relação entre humanos e animais no ambiente educacional pode ser potencializada. Contudo, requer preparo dos 


\section{Dossiê: Diálogos interdisciplinares em Psicologia da Educação \\ | Contribuições da Educação Assistida por Animais - EAA para a Psicologia da Educação: uma análise fenomenológica|}

\section{|Jean Marlos Pinheiro Borba |}

profissionais que conduzem a intervenção, quer sejam eles psicólogos, educadores ou profissionais de outras áreas do conhecimento (BORBA, 2015).

No Brasil, há cursos de formação básica em TAA/EAA oferecidos, por exemplo, ATEAC - Instituto para Atividades, Terapias e Educação Assistida por Animais de Campinas, Instituto Nacional de Ações e Terapia Assistida por Animais - INATAA. Em Portugal, o Instituto Superior de Psicologia Aplicada - ISPA já oferece pós-graduação presencial em Terapia Assistida por Animais - $\mathrm{TAA}^{7}$ vinculada ao Instituto de Psicologia. Excetuando-se a capacitação tradicional, o estudo e o envolvimento responsável e fundamentado sobre as IAA's podem ser feitos como alternativa à prática tradicional de intervenção feita por humanos, sem a presença de animais.

$\mathrm{Na}$ área da Psicologia, créditos devem ser dados à psicóloga e professora Vanessa Christina Breia que tem orientado excelentes trabalhos de conclusão de curso de graduação em Pedagogia como os de Roiffé (2009) e Ribeiro (2013) que apresentam resultados da inserção de futuros profissionais da Pedagogia no campo das IAA's. No curso de Pedagogia do Centro de Educação e Humanidades da Universidade do Estado do Rio de Janeiro - UERJ. A referida professora orienta trabalhos na área de concentração Educação Assistida por Animais - EAA, portanto, acreditamos ser a única com especificidade em EAA existente no país, segundo as pesquisas realizadas.

Atualmente, tenho desenvolvido visitação em asilo de mendicidade com animais, contribuindo, assim, para a consolidação do projeto de pesquisa Terapia Assistida com Animais - TAA uma alternativa para a formação em Psicologia: um estudo fenomenológico, que tem sido realizado desde o ano de 2015, com discentes do curso de Psicologia e História da UFMA. Leitura e discussão de estudos e pesquisas que subsidiam as IAA's na saúde têm sido realizados com os alunos na educação e em outras atividades. Faz parte, também, das atividades do grupo, o planejamento para realização de atividades de leitura assistidas com animais em escolas particulares e comunitárias, localizadas no bairro do São Francisco, como forma de possibilitar a vivência dos estudos na prática de intervenção.

Defende-se, seguindo a orientação husserliana não naturalista e antipsicologista (HUSSERL, 1965; 2009; 2012), que a fenomenologia busca compreender o que se apresenta e como se apresenta no mundo da vida. $\mathrm{Na}$ pesquisa realizada, deparei-me com estudos de diferentes orientações e isso só foi possível dado ao caráter intencional de não estabelecer hipóteses, mas de me movimentar intelectualmente na busca por conhecer o

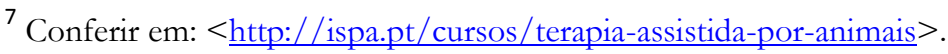


Dossiê: Diálogos interdisciplinares em Psicologia da Educação

| Contribuições da Educação Assistida por Animais - EAA para a Psicologia da Educação: uma análise fenomenológica|

|Jean Marlos Pinheiro Borba|

fenômeno da Educação Assistida por Animais - EAA assim como ele foi tratado na literatura. Destacamos ainda que a influência husserliana permite a compreensão de que o animal é um ente e, como tal, deve ser respeitado em sua singularidade como ser vivente e não como um recurso da ciência experimental.

\section{REFERÊNCIAS}

ABRAHÃO, F.; CARVALHO, M. C. Educação Assistida por Animais como recurso pedagógico na educação regular especial - uma revisão bibliográfica. Revista Científica Digital da FAETEC, Rio de Janeiro, v. 1, n. 1, 2015. Disponível em: $<$ http://www.faeterj-caxias.net/revista/index.php/edutec/index $>$. Acesso em: 01 jun. 2016.

ATEAC - Instituto para Atividades, Terapias e Educação Assistida por Animais de Campinas. Educação Assistida por Animais: o cão como recurso pedagógico. Disponível em: < http://ateac.org.br/educacao-assistida-por-animais-o-cao-como-recursopedagogico/>. Acesso em: 13 maio 2016.

BARBOSA, P. S. Dificuldades de aprendizagem. São Luís: UemaNet, 2015. Disponível em: < https://goo.gl/pVxBdi> . Acesso em: 18 abr. 2016.

BELLO, A. A. Introdução à Fenomenologia. Bauru, SP: EDUSC, 2006.

BORBA, J. M. P. Saúde na Infância, Medicalização da Existência e as Intervenções Assistidas por Animais - IAA's. In: DANTAS, J. B. (Org.). A Infância medicalizada: discursos, práticas e saberes para o enfrentamento da medicalização da vida. Curitiba: CRV, 2015. p. 243-274.

Terapia Assistida com Animais - TAA uma alternativa para a formação em Psicologia: um estudo fenomenológico. São Luís: UFMA, 2015. (Projeto de Pesquisa e Iniciação Científica - PIBIC).

CAMPOS, P. R. C. O tratamento e ajuda através dos animais. Curso de Técnico Auxiliar de Veterinária - SlideShare, 2009. Disponível em: $<$ http://pt.slideshare.net/hospvetporto/o-tratamento-e-ajuda-atravs-dos-animais4466011>. Acesso em: 05 abr. 2015.

CAPOTE, P. S. O.; COSTA, M. P. R. Terapia Assistida por Animais: aplicação no desenvolvimento psicomotor da criança com deficiência intelectual. São Carlos: EdUFSCar, 2011.

CARPIGIANI, B. Psicologia: das raízes aos movimentos contemporâneos. 3. ed. São Paulo: Cengage Learning, 2010.

CENTRO CULTURAL DO MINISTÉRIO DA SAÚDE - CCMS. Nise da Silveira: vida e obra. Disponível em: <http://www.ccms.saude.gov.br/nisedasilveira/preservacaomemoria.php>. Acesso em: 02 maio 2016. 
|Jean Marlos Pinheiro Borba|

COLOSIO, S. A. R. Avaliação de alterações de comportamento em crianças de uma creche após uso da terapia assistida por animais. 2009. 42 f. Monografia (Graduação em Psicologia) - Faculdades Integradas Fafibe, Bebedouro, SP, 2009. Disponível em: $<\underline{\text { http://unifafibe.com.br/revistasonline/arquivos/revistapsicologia/sumario/14/0612201 }}$ 0140325.pdf>. Acesso em: 02 maio 2016.

CONSELHO FEDERAL DE PSICOLOGIA. Atribuições profissionais do psicólogo no Brasil/CBO - Catálogo Brasileiro de Ocupações do MT. Disponível em: $<$ http://site.cfp.org.br/wp-content/uploads/2008/08/atr prof psicologo cbo.pdf $>$.

Acesso em: 03 fev. 2016.

DAINTY, S. Brincando com seu cão: 50 jogos para divertir você e o seu amigo fiel. São Paulo: Pensamento, 2009.

DILLON, J. Os gatos nunca mentem sobre o amor. São Paulo: Universo dos Livros, 2013.

DOTTI, J. Terapia \& Animais. São Paulo: PC Editorial, 2014.

GODOY, A. S.; DENZIN, S. S. Atividades assistidas por animais: aspectos revisivos sob um olhar pedagógico. Ensaios e ciência: C. Biológicas Agrárias e da Saúde, v. 5, n. 5, p. 14-22, 2007. Disponível em: <http://patastherapeutas.org/wpcontent/uploads/2015/07/Olhar-pedag $\%$ C2\%A2gico-da-TAA.pdf $>$. Acesso em: 05 abr. 2015.

GREIF, S. Alternativas ao uso de animais vivos na educação pela ciência responsável. São Paulo: Instituto Nina Rosa, 2003.

GUIMARAES, A. C. O conceito de mundo da vida. Cadernos da EMARF, Fenomenologia e Direito, Rio de Janeiro, v. 5, n. 1, p. 1-150, abr./set. 2012.

HUSSERL, E. A ingenuidade da ciência. Scientiæ Zudia, São Paulo, v. 7, n. 4, p. 659-667, dez. 2009. Disponível em: <http://www.scielo.br/scielo.phparttext\&pid=S167831662009000400008\&>. Acesso em: 03 out. 2015.

(1900-1901). Investigações Lógicas: Prolegômenos à Lógica Pura. Rio de Janeiro: Forense, 2014.

(1911). A filosofia como ciência de rigor. Lisboa: Atlantida, 1965.

(1935). A crise das ciências européias e a fenomenologia: uma Introdução à Filosofia Fenomenológica. Rio de Janeiro: GEN, 2012.

LERMONTOV, T. A Psicomotricidade na Equoterapia. Aparecida, SP: Ideias e Letras, 2004.

MARX, M. H.; HILLIX, W. A. Sistemas e teorias em psicologia. 3. ed. São Paulo: Cultrix, 1978.

MARTINS, M. F.; BALBINI, N. W.; STANQUINI, C. S. Terapia nas escolas: lições do passado e desafios para o futuro. In: SIMPÓSIO DE PÓS-GRADUAÇÃO E PESQUISA 
EM NUTRIÇÃO E PRODUÇÃO ANIMAL, 8., 2014, Pirassununga, SP. Anais eletrônicos... Pirassununga: FMVZ/USP, 2014. Disponível em: $<$ http://posvnp.org/simposios/2014/resumos/MariadeFatimaMartins.pdf $>$. Acesso em: 02 jun. 2016.

Animais na escola. In: DOTTI, J. Terapia \& Animais. Osasco: Livrus, 2014.

MASCARENHAS, Â. M. D. V. Educação Assistida por Animais: intervenção em crianças com alterações de comportamento. 2010. 128 f. Dissertação (Mestrado em Ciências da Educação, Educação Especial) - Escola Superior de Educação de Paula Frassinetti, 2010 Porto, Disponível em:

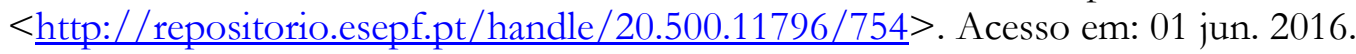

MELO, L. F. Impacto da intervenção assistida por animais nas habilidades sociais, motivação e estresse em crianças cursando o ensino fundamental: um estudo etológico, neurofisiológico e neuropsicológico. 2014. 139 f. Tese (Doutorado em Ciências do Comportamento) - Instituto de Psicologia, Universidade de Brasília - UNB, Brasília, 2014. Disponível em: < http://repositorio.unb.br/handle/10482/16888>. Acesso em: 01 jun. 2016.

MENEZES FILHO, A. S.; GURGEL, W. B. Ética e experimentação animal: a questão do especifismo nas ciências experimentais. Cadernos de Pesquisa, São Luís, v. 18, n. 3, p. 40-53, set./dez. 2011. Disponível em: $<$ http://www.periodicoseletronicos.ufma.br/index.php/cadernosdepesquisa/article/view/ 643/397>. Acesso em: 15 jun. 2016.

PETENUCCI, A. L. Educação assistida por animais. In: CHELINI, M. O. M.; OTTA, E. Terapia Assistida por Animais. Barueri, SP: Manole, 2016.

PORTO, Í. M. R. Desenvolvimento infantil e a dimensão lúdica. São Luis: UemaNet, 2015.

RIBEIRO, D. C. C. O Pedagogo na Equoterapia focando crianças com Encefalopatia Crônica Não Progressiva da Infância (ECNPI - Paralisia Cerebral). 2013. 86 f. Monografia (Graduação em Pedagogia Plena) - Faculdade de Formação de Professores, Universidade do Estado do Rio de Janeiro - UERJ, São Gonçalo, RJ, 2013. Disponível em: < http://www.ffp.ueri.br/arquivos/dedu/monografias/dccr.pdf $>$. Acesso em: 30 abr. 2016.

RICHARDSON, R. J. Pesquisa Social: métodos e técnicas. São Paulo: Atlas, 1999.

ROIFFÉ, F. I. L. S. Crianças e cães na escola: uma educação mais que especial. 2009. 77 f. Monografia (Graduação em Pedagogia Plena) - Faculdade de Formação de Professores, Universidade do Estado do Rio de Janeiro - UERJ, São Gonçalo, RJ, 2009. Disponível em: $<$ http://www.ffp.ueri.br/arquivos/dedu/monografias/FILSR.2009.pdf $>$. Acesso em: 30 abr. 2016.

SINGER, P. Libertação Animal. São Paulo: WMF Martins Fontes, 2010.

SILVEIRA, N. Gatos: a emoção de lidar. Rio de Janeiro: Léo Christiano Editorial, 1998. 
Dossiê: Diálogos interdisciplinares em Psicologia da Educação

| Contribuições da Educação Assistida por Animais - EAA para a Psicologia da Educação: uma análise fenomenológica|

|Jean Marlos Pinheiro Borba|

VERGARA, S. C. Projetos e Relatórios de Pesquisa em Administração. São Paulo: Atlas, 1998. 